\title{
TOMÁS DE AQUINO E A RAZÃO NATURAL DOS DIREITOS HUMANOS: PESSOA E BEM COMUM
}

\author{
AQUINAS AND NATURAL REASON OF HUMAN RIGHTS: PERSON AND \\ COMMON GOOD
}

\author{
Elden Borges Souza \\ Universidade Federal do Pará - UFPA - Tucuruí - Pará - Brasil \\ Victor Sales Pinheiro \\ Universidade Federal do Pará - UFPA - Tucuruí - Pará - Brasil
}

\begin{abstract}
Resumo: A atual defesa dos direitos humanos reavivou a discussão acerca da fundamentação do direito. O pensamento do Positivismo Jurídico que igualou o direito à lei passou a ser contestado em razão da necessidade de garantias da pessoa contra o poder político. Dessa forma, o presente trabalho apresenta a concepção de Tomás de Aquino acerca do direito, da lei e da justiça e analisa como o positivismo contrapôs-se a esse posicionamento, levando a uma contradição com a defesa dos direitos humanos. Como consequência, analisase uma proposta de fundamentação dos direitos humanos na Filosofia Tomista. No contexto de discussões sobre Filosofia do Direito, o objetivo do presente trabalho é analisar como os conceitos de Direito e de Justiça em Tomás de Aquino, fundados nas ideias de pessoa, bem comum e lei natural, podem fundamentar a concepção contemporânea dos direitos humanos. A metodologia empregada foi de pesquisa bibliográfica. Após a identificação da insuficiência do Positivismo Jurídico, o presente trabalho identificou na posição de Aquino uma possibilidade que assegura uma base para os direitos humanos que não se subordina ao Poder do Estado e sem os problemas da visão moderna de direito natural.
\end{abstract}

Palavras-chave: Direitos Humanos. Filosofia do Direito. Lei Natural. Positivismo Jurídico. Tomás de Aquino.

\footnotetext{
Abstract: The current human rights defense revived the discussion on the basis of law. The thought of Legal Positivism who equaled the law to act began to be challenged because of the need for guarantees of the person against political power. Thus, this paper presents the design of Thomas Aquinas about the law, the right and the justice and analyzes how positivism countered to this position, leading to a contradiction with human rights. As a result, it analyzes a proposal for a foundation of human rights in Aquinas' philosophy. In the context of discussions on Law Philosophy, the objective of this study is to analyze how the concepts of law and justice in Aquinas, founded in the ideas of person, the common good and natural law, can justify the contemporary conception of human rights. The methodology used was literature search. After identifying the failure of Legal Positivism, this study identified the Aquinas' position as a Revista do Direito UNISC, ISSN: 1982-9957 
possibility that ensures a basis for human rights that is not subject to the power of the state and without the problems of the modern view of natural law.

Keywords: Aquinas. Human Rights. Law Philosophy. Legal Positivism. Natural Law.

\section{Introdução}

Durante muito tempo houve uma batalha entre as concepções Positivista e Jusnaturalista de Direito. No entanto, as várias concepções de Positivismo Jurídico acabaram prevalecendo e a defesa da lei natural pareceu tornar-se um elemento mais histórico do que jurídico. O direito, então, passou a ser associado à lei positiva e toda ordem não criada pela vontade humana foi relegada às esferas moral e política, não passíveis de conhecimento pelo jurista.

Entretanto, a avalanche contemporânea dos direitos humanos trouxe novamente ao centro do debate a discussão sobre um fundamento além da lei positiva. A necessidade de afirmar garantias da humanidade independentemente da aquiescência do poder político reavivou o debate sobre a lei natural e os limites do normativismo - que igualou lei positiva e direito. Tendo sido historicamente uma afirmação do Jusnaturalismo, a defesa dos Direitos do Homem ou Direitos Humanos sempre foi um desafio ao Positivismo Jurídico.

Entre os autores que expressaram uma firme defesa da lei natural está Tomás de Aquino. Sua posição ainda é retomada contemporaneamente para contraposição ao positivismo, como por John Finnis (2012, p. 12). Partindo da ideia de que a pessoa humana é anterior ao direito positivo e o seu real fundamento, o pensamento tomista limita o positivo por balizas da justiça, que está assentada naquilo que é devido por natureza.

Nesse sentido, a proposta do presente trabalho é analisar a possibilidade de fundamentação dos direitos humanos na Filosofia do Direito tomista, como uma forma de superar as contradições que podem ser identificadas na defesa desses direitos a partir de uma concepção positivista.

A partir da apresentação da posição de Tomás de Aquino acerca do direito, da lei e da justiça será analisada como o positivismo contrapôs-se a 
esse posicionamento e como essa mudança de concepção levou a uma contradição com a afirmação dos direitos humanos. Considerando esses dois temas, a questão posta é como o pensamento tomista pode permitir uma compreensão adequada de direitos humanos que não seja utópica nem irrelevante.

\section{A concepção tomista do direito e da lei}

A análise da compreensão de Tomás de Aquino acerca do direito e da lei deve basear-se fundamentalmente em uma distinção: a lei e o direito não se confundem, embora estejam relacionados. Portanto, em seu pensamento o conhecimento e a aplicação da lei não esgota o conceito de direito.

Essa distinção básica é clara dentro da Suma Teológica. Partindo na Parte I das questões sobre Deus, a lei está inserida na Seção I da Parte II, que faz referência ao homem. As diversas leis são agrupadas como mecanismos divinos para pedagogia humana (VOEGELIN, 2012, p. 260). Por sua vez, o direito é analisado de forma mais detida na Seção II da Parte II, dentro da análise das virtudes cardeais - inserido na virtude da justiça (que é, inclusive, a virtude com maior número de questões).

A separação parcial entre a lei e o direito, bem como a relação umbilical deste com a Justiça, é uma diferença radical em relação ao modelo jurídico defendido pela dogmática positivista contemporânea. Embora o pensamento de Tomás de Aquino não seja inteiramente novo - pois está baseado na concepção aristotélica de justiça (ISRÄEL, 2009, p. 10) -, apresenta uma sistematicidade ímpar.

Para que o entendimento do pensamento tomista seja completo será necessário realizar uma inversão estrutural na Suma Teológica, apresentando primeiramente a relação entre o direito e a justiça e, posteriormente, a relação destes conceitos com as diversas leis.

A obra que representa o ápice do pensamento jurídico - ou, o que foi denominado posteriormente de Filosofia do Direito - de Tomás de Aquino é a Suma Teológica (RAMPAZZO; NAHUR, 2015, p. 7). Não obstante, não estão 
formuladas questões referentes propriamente ao direito, e sim à justiça englobando o direito.

Em sua análise, a primeira preocupação de um jurista deve ser observar que o termo direito possui uma pluralidade de aplicações (AQUINO, 2015, II-II, q. 57). No entanto, constitui um erro ignorar o conceito próprio de lus e substituí-lo pelos diversos outros usos. A relação básica e necessária a ser feita é entre Direito (Ius) e Justiça (Iustitiae), porque diz respeito ao que é justo (AQUINO, 2015, II-II, q. 57).

Nesse sentido, entre a pluralidade de aplicações, o conceito de direito caracteriza-se como o objeto da justiça, pois implica ordenar o homem no que diz respeito ao outro. Isso diferencia a virtude da justiça das demais virtudes. Enquanto as outras virtudes dizem respeito ao próprio agente, a justiça é de caráter relacional (BARZOTTO, 2010, p. 71), isto é, se dá na relação com o outro - na atribuição do justo, do direito (AQUINO, 2015, II-II, q. 57).

Para proceder tal atribuição do justo é necessária, portanto, uma concepção de igualdade. Então, conclui Tomás de Aquino, o fundamento da igualdade caracteriza o direito. A igualdade pode ser em virtude da natureza da coisa ou pode ser uma igualdade convencional (por uma convenção pública ou particular). Quando o justo se funda em uma igualdade que não depende da vontade humana (quer de um indivíduo, quer de um povo), trata-se do direito natural. Quando, por outro lado, o justo decorre de uma convenção, tem-se o direito positivo (AQUINO, 2015, II-II, q. 57).

Uma primeira conclusão deste pensamento é clara de que a igualdade convencional tem limite na natureza das coisas. Sendo assim, a vontade humana não pode definir plenamente o justo, uma vez que existe uma igualdade na própria natureza que não está disponível ao legislador ou aos particulares. Existe, portanto, uma baliza dentro da qual o justo convencional (ou direito positivo) pode ser definido, sem afrontar o justo natural (AQUINO, 2015, II-II, q. 57).

Em segundo lugar, essa naturalidade da igualdade não significa que o justo esteja completamente fixo, de forma rígida e imutável, pela eternidade. $O$ justo natural não congela a humanidade, que é naturalmente mutável (AQUINO, 2015, II-II, q. 57). É necessário compreender, portanto, que existe 
uma margem para atuação do direito positivo e concretização das particularidades de um tempo ou povo.

A justiça, por sua vez, caracteriza-se pela vontade constante e perpétua de dar a cada um o seu direito - ou, o que é seu. Não se trata de uma potência e sim e de um ato; e não de um ato isolado, mas de um hábito - o que caracteriza a virtude (AQUINO, 2015, II-II, q. 58). Este hábito pressupõe alteridade, pois exige uma relação de igualdade entre os indivíduos na atribuição daquilo que lhes é por direito (AQUINO, 2015, II-II, q. 58).

Nesse aspecto, Tomás deixa claro que a justiça não se confunde com a liberalidade, a benignidade ou a misericórdia. Considerando o reconhecimento do outro, também se reconhece o seu direito, dando-Ihe não outra coisa, e sim o que lhe pertence, o que é seu (AQUINO, 2015, II-II, q. 58). Obviamente a sociedade e as relações humanas em geral não precisam estar baseadas unicamente na justiça, a liberalidade é desejável - mas não se confunde com a justiça (HERVADA, 2006, p. 40).

É nesse ponto que há a conexão entre o direito, a justiça e a lei. Sendo a justiça o hábito de realizar o justo, isto é, de aplicar o direito, é necessário um título e uma medida que definam o que é o direito. Retoma-se, assim, a questão da igualdade. Deve existir um padrão que defina a igualdade e, dessa forma, o direito que cabe a cada um. Trata-se de uma espécie de título (HERVADA, 2006, p. 54).

A necessidade desse título é de caráter lógico. O direito positivo, como visto, pressupõe um critério de justiça. Portanto, o justo é anterior ao direito positivo. Por sua vez, a justiça dá a cada um o que é seu. Portanto, há um direito de outra ordem anterior à justiça, o direito natural. Contudo, esse direito pressupõe uma atribuição de cada coisa ao seu titular, uma divisão. Esse ato primeiro é realizado pela lei natural. Sendo assim, “a justiça por si só não reparte as coisas, mas pressupõe uma divisão já estabelecida pela natureza, por lei humana ou por pacto" (HERVADA, 2006, p. 39).

No pensamento de Tomás de Aquino, o título - que não se confunde com o fundamento - do direito é a lei. Essa relação de anterioridade é percebida até pela estrutura da Suma, como já explicado. O direito supõe, assim sendo, uma divisão de bens entre as pessoas, e a justiça está na 
atribuição daquilo que pertence a cada um - pelo que a lei é essencial. No entanto, deve ficar claro que a lei tem uma finalidade muito maior que definir o direito, ela é um instrumento divino que move exteriormente o homem ao bem (AQUINO, 2015, I-II, q. 90).

Em primeiro lugar, a lei é essencialmente uma manifestação da razão e não da vontade - mesmo em se tratando da lei humana (AQUINO, 2015, I-II, q. 90). Pertence à razão, pois a razão é "a regra e a medida dos atos humanos" e, por sua vez, "a lei é certa regra e medida dos atos, segundo a qual alguém é levado a agir, ou a apartar-se da ação" (AQUINO, 2015, I-II, q. 90, a.1). A racionalidade da lei está voltada à ordenação para o bem comum, que não ignora os fins particulares (AQUINO, 2015, I-II, q. 90).

A partir disso, Tomás vai expor como a diversidade de leis contribui para a realização do bem comum, conforme a providência divina. Na divisão, alguns autores reconhecem a existência de seis espécies de lei: eterna, natural, humana, divina antiga, divina nova e do pecado (RAMPAZZO; NAHUR, 2015, p. 121). No entanto, outra corrente agrupa as leis em apenas quatro espécies: eterna, natural, humana e divina - antiga e nova (BASTIT, 2010, p. 72).

O ponto de partida para a construção dessa divisão reside na ordenação presente na criação mundo. A ordem pressupõe uma finalidade, que somente pode ter sido infundida pelo Criador. Portanto, Tomás de Aquino defende a existência de uma ordem natural dada pelo Logos Divino, que atribuiu ao homem uma finalidade. Esta finalidade concretiza a plenitude humana e reside em Deus (VOEGELIN, 2012, p. 242). A lei, nesse sentido, é um instrumento para realização do fim do ser humano.

A ordem, portanto, sendo uma manifestação da razão divina, está assentada em uma primeira lei, a lei eterna. Essa lei é exatamente o governo do Logos Divino sobre o cosmos, que não está condicionada a um tempo específico, sendo eterna (AQUINO, 2015, I-II, q. 91). E é dado às criaturas participar dessa razão. Por meio de tal participação o ser humano pode, racionalmente, discernir entre o bem e o mal, o que se dá por meio da lei natural (AQUINO, 2015, I-II, q. 91).

Embora o elemento teológico seja central no pensamento de Tomás de Aquino, não é o único fundamento de sua argumentação. Como ser social, a 
ordem é necessária à sociedade e ao homem, o que evidencia a existência de uma lei natural que limita a criação do direito pela vontade humana. Há uma igualdade objetivamente compreensível e a própria plenitude do homem depende de uma sociedade ordenada na busca do bem comum - que, repisese, inclui a realização dos fins particulares.

Apesar da importância atribuída à lei natural, a lei positiva é um elemento indispensável no pensamento tomista e não pode ser ignorada. $O$ homem é um ser histórico e sujeito a diversas contingências, um ser no tempo e no espaço. Portanto, a lei natural não pode ser considerada isoladamente, pois é incapaz de dar toda a regulamentação que a sociedade necessita. A lei positiva é não apenas possível, é extremamente necessária (AQUINO, 2015, III, q. 91).

As contingências das sociedades não são ignoradas, pois cabe à lei humana incluí-las. A afirmação de defensores da Lei Natural de que o legislador somente pode atuar na esfera do indiferente (HERVADA, 2006, p. 63) não significa - ao menos a partir de uma leitura tomista - que a lei humana é irrelevante ou indiferente para as questões de direito, isto é, de definir o justo.

Ao contrário, o centro da discussão acerca das leis natural e positiva não pode ser reduzida à ideia de que somente a lei natural apresenta um conteúdo significativo, enquanto a lei positiva pode ser completamente dispensada. A compreensão analógica de Tomás de Aquino coloca a lei positiva como instrumento de realização espaço-temporal do justo. A ordem é viabilizada por meio da aplicação da lei positiva. Contudo, sendo instrumento de concretização da lei natural, não pode afrontá-la (AQUINO, 2015, I-II, q. 95).

A liberdade do legislador somente existe naquilo que for indiferente, no sentido de matéria não delimitada pela lei natural, como é o caso do corriqueiro exemplo do sentido das vias para os automóveis (HERVADA, 2006, p. 63; RAMPAZZO; NAHUR, 2015, p. 38). Nos demais casos, por existir uma igualdade e uma lei que definem o justo por natureza, a lei positiva encontra balizas que limitam sua atuação, mas que não a tornam inútil.

Pois bem, Deus revela seu plano (lei eterna) à humanidade (em geral) e ao homem (de forma individualizada) por meio da lei natural. Isso funciona como princípios gerais, dependendo de uma concretização na sociedade por 
meio da lei positiva humana. Não obstante, para a plena realização da razão divina outra espécie de lei é necessária, a lei divina.

Em sua visão, quatro motivos tornam necessária a lei divina. Em primeiro lugar, porque o homem não está ordenado apenas a um fim finito, mas à bem-aventurança eterna. Em segundo lugar, para evitar a incerteza do juízo humano, que produz leis contrárias. Em terceiro lugar, apesar de a lei humana não poder coibir e ordenar atos interiores, a virtude exige sua adequação. Por fim, não é adequado ao bem comum que a lei humana puna ou proíba todos os males, pelo que a proibição e punição dos que lhe escapam são de atribuição da lei divina (AQUINO, 2015, I-II, q. 91).

Esse conceito de lei divina subsite na História de duas formas: a lei antiga e a lei nova. Não se tratam de leis diversas, e sim de formas distintas de como a lei divina se deu aos homens - mantendo a mesma espécie (AQUINO, 2015, I-II, q. 91). Diferentemente da lei natural, ligada à criação - e, por conseguinte, à estrutura natural das coisas -, a lei divina relaciona-se com 0 plano de redenção - dividindo-se entre a fase anterior e posterior a Cristo.

A relação entre as leis natural, divina e humana aponta para uma sutil separação entre as esferas da religião e da política. A lei divina não dependerá de uma atuação do poder temporal para ser efetivada - exatamente pelos problemas que visa responder e por tratar de um relacionamento transcendente que diz respeito a Igreja e a Deus. Por outro lado, por sua generalidade, a lei natural relaciona-se intimamente com a positivação, pois necessita da executoriedade do poder temporal no que diz respeito à comunidade e ao bem comum (VOEGELIN, 2012, p. 262).

Por fim, o que alguns autores (RAMPAZZO; NAHUR, 2015, p. 127) trataram como sendo outra espécie de lei em Tomás de Aquino, na realidade deve ser observado como um desvio da lei. Sendo a razão integrante do conceito de lei, a lei do pecado (da concupiscência) em realidade configura-se como uma deturpação, pois não contribui nem ao bem comum, nem conduz à finalidade do homem (AQUINO, 2015, I-II, q. 91). Esta lei não pode ser considerada propriamente lei no pensamento tomista, pois é dever do homem afastar-se dela. 
Pelo exposto, a justiça relaciona-se intimamente com o direito e a lei, promovendo uma ligação entre esses conceitos. Sendo que o direito e a lei não ignoram a importância do legislador, no entanto não se resumem às suas decisões. Afinal, se a justiça decorresse apenas do direito positivo, o justo residiria em aplicar tal lei. Nesse caso, o justo seria uma concessão do parlamento, do governo ou da sociedade. Sem o direito natural a justiça tornase uma formalidade.

\section{A insuficiência do positivismo para os direitos humanos}

O Positivismo Jurídico não é uma corrente de pensamento completamente uniforme. Ao contrário, em seu seio muitas teorias foram desenvolvidas e o pensamento desenvolvido principalmente por Kelsen (2009) foi aprimorado por Hart (2009) e, atualmente, Raz (2012).

Apesar disso, há um centro em torno do tal giram todas essas variantes. Essa ideia central parte da rejeição - mais intensa ou mais branda - de um direito natural, a partir da afirmação que o direito é originado pela vontade humana, quer pela lei, quer pelo costume, quer pelo contrato (HERVADA, 2006, p. 59-60). Portanto, aquela divisão que origina o que é devido a alguém somente decorre de uma igualdade convencional.

A preocupação positivista em geral é tornar o Direito uma ciência, utilizando-se dos padrões dados pelas ciências naturais. Kelsen (2009, p. 85) deixa claro seu objetivo ao tentar comparar as ciências sociais às ciências naturais, buscando objetividade e, consequentemente, cientificidade. Para Bobbio (1995a, p. 131), o Direito é um fato e não um valor, o que permite que o jurista estude-o como um cientista estuda a realidade natural.

$\mathrm{Na}$ sua definição da norma jurídica, o positivismo esforça-se, principalmente, para diferenciar as diversas espécies de normas existentes, para encontrar o conceito da norma jurídica. Para Bobbio (2001, p. 147-148), não é suficiente a distinção com base em um critério material, como relação intersubjetiva ou finalidade. A proposta do positivista é definir como jurídica uma norma conforme o sujeito que a estabeleceu (BOBBIO, 2001, p. 149). 
O critério do sujeito define a norma jurídica independentemente da forma que assume ou do fim a que se propõe. Considera-se jurídica a norma posta pelo poder soberano - embora os caminhos utilizados pelos diversos autores tenha alguma variação. Tais normas tornam-se essenciais, pois o poder soberano detém o monopólio da força e, por consequência, a capacidade de fazê-las valer (BOBBIO, 2001, p. 150).

Considerando que nem toda manifestação da vontade humana será caracterizada como lei, é necessário um procedimento específico para criar uma norma jurídica ${ }^{1}$. Assim, ao lado das normas de conduta, existem normas de estrutura ou de competência, as quais fixam "as condições e os procedimentos através dos quais emanam normas de conduta válidas" (BOBBIO, 1995b, p. 33).

Por consequência, para um positivismo clássico a estrutura do ordenamento jurídico firma-se nas ideias de unidade, sistematicidade e completude. Portanto, são rejeitados problemas hierárquicos, de antinomia e de lacunas. Mesmo as dificuldades decorrentes da diversidade de ordenamentos encontram soluções (formais) - o que asseguraria segurança jurídica (BOBBIO, 1995b, p. 34-35).

No entanto, a solução para todos os problemas identificados, ao final, encontra a mesma resposta: a soberania estatal. Sobre a pedra fundamental do Estado está assentada a unidade, a sistematicidade e a completude do ordenamento jurídico. Todas as normas, mesmo as particulares, retiram sua validade do Estado-Soberano, que se caracteriza como a fonte das fontes (BOBBIO, 1995b, p. 41) - ideia diametralmente oposta à de Tomás de Aquino.

Uma vez que o próprio ordenamento regula o modo pelo qual se devem produzir as normas, a sua unidade depende de uma norma fundamental que autoriza todas as demais (KELSEN, 2009, p. 217). Afinal, toda norma pressupõe um (e deriva de um) poder normativo, que também pressupõe uma norma que o autorize a produzir normas jurídicas. Logo, no caso do poder constituinte essa norma pressuposta é a norma fundamental, caracterizando-o como jurídico e servindo como fundamento de validade de todas as normas do sistema (BOBBIO, 1995b, p. 58).

\footnotetext{
${ }^{1}$ Este é um ponto que Tomás de Aquino já havia reconhecido (AQUINO, 2015, q. 90). Revista do Direito UNISC, ISSN: 1982-9957 Santa Cruz do Sul №. 48 | p. 70-91 | JAN-ABR 2016 https://online.unisc.br/seer/index.php/direito/index
} 
A preocupação positivista de defender uma norma pressuposta é a preocupação de afastar a ideia de que o direito seja fruto unicamente da força. Afinal, sem qualquer baliza material, o que restaria ao positivismo seria reconhecer que o mais forte decide o que é jurídico ou não. A ideia de uma norma fundamental poderia afastar essa conclusão, mas na prática essa norma não garante qualquer materialidade ao direito subsequente. Como consequência, o direito permanece dissociado de qualquer critério de justiça:

\begin{abstract}
A definição do Direito, que aqui adotamos, não coincide com a de Justiça. A norma fundamental está na base do Direito como ele é (o Direito positivo), não do Direito como deveria ser (o Direito justo). Ela autoriza aqueles que detêm o poder a exercer a força, mas não diz que o uso da força seja justo só pelo fato de ser vontade do poder originário. Ela dá uma legitimação jurídica, não moral, do poder. $O$ Direito, como ele é, é expressão dos mais fortes, não dos mais justos (BOBBIO, 1995b, p. 67).
\end{abstract}

No entanto, essa proposta acaba por contradizer os objetivos dos direitos humanos, de uma luta contra a opressão estatal e uma garantia jurídica para o indivíduo não criada pelo poder do legislador. Esse problema surge principalmente em razão da recusa do caráter jurídico a qualquer fundamento não positivado.

Dentro de uma ótica positivista os documentos internacionais podem suprir uma discussão por fundamentos. No entanto, ao menos quatro razões levam à busca por esse fundamento (ROBLES, 2005, p. 1-2). Em primeiro lugar, é absurdo defender um valor sem saber o motivo. Em segundo lugar, um fundamento delimita um conteúdo concreto ao que se denomina "Direitos Humanos". Em terceiro lugar, não é possível apresentar uma teoria sobre os direitos humanos sem fundamentá-los. Por fim, para a efetivação de direitos é indispensável a existência de ideias claras.

Da necessidade de fundamentação também se conclui que nem tudo pode ser denominado "Direitos Humanos". Da exposição de um positivista como Bobbio (2004, p. 15-16) qualquer pretensão amplamente aceita e defendida, uma vez positivada, pode ser considerada como essa espécie de direito. Em essência, não se pode extrair uma distinção positivista entre os direitos em geral e os direitos humanos.

O principal contrassenso em uma posição positivista acerca dos direitos humanos - como a de Norberto Bobbio (2004, p. 4) - é ao mesmo tempo 
defender esses direitos como fruto da inversão na relação indivíduo-Estado, mas condicioná-los ao reconhecimento pelo Estado ou pela Comunidade Internacional. A definição do que são direitos humanos, portanto, permanece sujeita à decisão de um corpo político.

O paradoxo é autoevidente quando percebemos que no Positivismo Jurídico nada resta ao indivíduo sem o Estado ou sem a Comunidade Internacional. De forma involuntária e inevitável retorna-se ao ponto de partida: sem a comunidade o indivíduo não tem mais do que meros desejos e pretensões sem eficácia - pois esta depende do poder político.

Nesse sentido, interessante observar o ceticismo positivista em relação a um direito inerente ao homem ou que possa existir antes e independente de qualquer benevolência do Estado - noção essa que foi o germe histórico do conceito de direitos humanos:

\footnotetext{
Falar de direitos naturais ou fundamentais, inalienáveis ou invioláveis, é usar fórmulas de uma linguagem persuasiva, que podem ter uma função prática num documento político, a de dar maior força à exigência, mas não têm nenhum valor teórico, sendo portanto completamente irrelevantes numa discussão de teoria do direito (BOBBIO, 2004, p. 6).
}

Essa conclusão parte de uma premissa positivista de que todos os direitos criados pela vontade humana possuem o mesmo fundamento de validade: o poder soberano. No entanto, se o fundamento da liberdade e dos demais direitos é a norma positiva - quer de um Estado, quer em âmbito internacional -, não há motivo para afirmar um deles como mais fundamental, se não baseado em um critério de hierarquia (formal) das normas - o que reduz a importância dos direitos humanos.

Prosseguindo, em sua concepção positivista, Bobbio (2004, p. 72-73) assume que, se um direito não é afirmado pela legislação e, simultaneamente, dotado de efetiva aplicação, não passa de mera obrigação moral ou, no máximo, política. Em tal situação, sem positivação plena (legislada e efetivada), os direitos humanos seriam uma carta de intenções, sustentada unicamente pela opinião pública.

Na prática, essa ideia reduz os direitos humanos a um instrumento de retórica internacional ou nacional: 
Partilho a preocupação dos que pensam que chamar de "direitos" exigências (na melhor das hipóteses) de direitos futuros significa criar expectativas, que podem não ser jamais satisfeitas, em todos os que usam a palavra "direito" segundo a linguagem corrente, ou seja, no significado de expectativas que podem ser satisfeitas porque são protegidas.

Por prudência, sempre usei, no transcorrer desta minha comunicação, a palavra "exigências" em vez de "direitos", sempre que me referi a direitos não constitucionalizados, ou seja, a meras aspirações, ainda que justificadas com argumentos plausíveis, no sentido de direitos (positivos) futuros (BOBBIO, 2004, p. 72).

Quando o positivismo reduz os direitos humanos a exigências de positivação de determinadas pretensões em um ordenamento (BOBBIO, 2004, p. 74), está novamente a condicionar esses direitos à vontade do Estado. Não passam de um conjunto de argumentos, que, se não positivados e aceitos pelo Poder Estatal, interessam somente a teóricos.

Tal posição, portanto, desloca os direitos humanos do jurídico para 0 exclusivamente político. Afinal, sem o reconhecimento pelo Estado a discussão não é jurídica, e sim sobre pautas políticas - não vinculantes - para o funcionamento das instituições públicas. Sem essa decisão estatal nada existe:

Uma coisa é ter um direito que é, enquanto reconhecido e protegido; outra é ter um direito que deve ser, mas que, para ser, ou para que passe do dever ser ao ser, precisa transformar-se, de objeto de discussão de uma assembleia de especialistas, em objeto de decisão de um órgão legislativo dotado de poder de coerção (BOBBIO, 2004, p. 77).

Como consequência, os direitos humanos seriam uma semente que apenas cresce no fértil solo do Estado de Direito. Somente em um Estado comprometido com a observância das normas (tanto internas, quanto internacionais) e que possui uma estrutura capaz de efetivá-los (ao menos progressivamente) podem ser reconhecidos direitos humanos. Mal comparando, é como a Teoria da Justiça de Rawls (2008, p. 560), que somente é aplicável em uma sociedade bem-ordenada.

Não obstante, quem mais necessita da proteção dos direitos humanos em face do Poder Público é o povo de um Estado de não direito, no entanto são exatamente esses que se recusam a aceitar limites ao seu poder. E mais, são esses Estados que rejeitam as normas internacionais.

No entanto, existe uma questão ainda mais profunda não respondida: e se a luta por esses direitos não for vitoriosa circunstancialmente, as pretensões 
de direitos nada significaram? Antes da II Guerra Mundial a proibição da tortura, dos tratamentos cruéis e do genocídio era despida de caráter jurídico? Antes do reconhecimento dos direitos civis dos negros americanos não existiam direitos?

O problema dessa visão positivista do Direito é que ao tratar os direitos humanos afastados de uma noção de Lei Natural acaba por negar a possibilidade de rejeição a um sistema normativo que não os reconheça (NINO, 2011, p. 27). Como consequência, eles não servem para impugnar juridicamente um ordenamento positivado - a menos que também sejam positivados, o que é paradoxal.

E ainda que seja admitido que a positivação internacional é suficiente, essa ideia continua reduzindo os direitos humanos a um ato de vontade ou de desejo da reunião de Estados. Considerando o ceticismo positivista, não existe essa coisa chamada "Comunidade Internacional" de uma maneira transcendente e que consolida as melhores ideias de justo, bem e paz. O que existe é a reunião de Estados soberanos em organismos internacionais.

O condicionamento do reconhecimento de direitos humanos à aprovação de documentos internacionais é reconhecer que uma votação - que pode ser marcada por fatores contingentes - tem a capacidade de dizer quais são os direitos mais básicos do ser humano. São os próprios Estados decidindo voto a voto o que irão aceitar como limites ao seu poder e como compreendem a dignidade humana.

A busca por um fundamento é a busca por algo além da lei positiva que justifique a defesa desses direitos. É a busca por uma base sólida que proteja o homem contra mudanças eventuais no consenso. Jacques Maritain (1966, p. 83), que participou da comissão de elaboração da Declaração Universal, é enfático ao rejeitar a defesa dos Direitos Humanos por uma ótica positivista:

\footnotetext{
O fundamento filosófico dos Direitos do Homem é a Lei Natural. Lamento não podermos encontrar outra palavra! [...]. Eles [os críticos] deveriam, entretanto, lembrar-se de que a história dos direitos do homem está ligada à história da Lei Natural, e que o descrédito em que, por certo tempo, o positivismo lançou a ideia da Lei Natural, provocou inevitavelmente um descrédito semelhante para a ideia dos direitos do homem.
} 
Nesse sentido, Strauss (2014, p. 3) explica que o Positivismo reduz o Direito às decisões dos legisladores e dos tribunais. Logo, seria a manifestação de determinadas preferências, o que acarreta a permissibilidade de qualquer ato (STRAUSS, 2014, p. 6). Somente o que o Estado ou a ONU disserem -e tudo aquilo que eles disserem - que é direito humano será efetivamente direito.

Por isso, a defesa dos direitos humanos a partir do Positivismo Jurídico conduz a diversos problemas e, ao fim, à inutilidade jurídica desse conceito. É necessária uma proposta assentada em outra concepção de direito e de lei.

\section{Uma proposta de fundamentação em tomás de aquino}

A partir da delimitação da Filosofia do Direito de Tomás de Aquino e da crise dos direitos humanos em uma lógica positivista é possível formular uma proposta de fundamentação nos conceitos tomistas de Lei Natural e de Direito Natural. Não apenas isso, como também a relação destes conceitos com as ideias de pessoa humana e comunidade política.

De início, deve ser observado que Tomás de Aquino separa as esferas natural e sobrenatural da teologia. Isso permite que a parte natural seja integrada num sistema humano sob a autoridade da razão e que a Revelação e a Igreja ocupem-se da esfera do sobrenatural. Tal divisão permite a apropriação do pensamento filosófico tomista independentemente do critério de fé, pois a razão caracteriza o homem e é capaz de chegar à verdade (VOEGELIN, 2012, p. 244).

Partindo dessa premissa, na concepção de Tomás de Aquino o direito não é pura subjetividade - quer como interpretação, quer como ato de poder de um sujeito (como o legislador). Ao contrário, o direito pode ser conhecido por intermédio da razão, não apenas por ser criado pela vontade humana (direito positivo), mas principalmente porque a razão consegue entender a igualdade decorrente da natureza. Portanto, o justo é objetivo, o que faz com que a positivação possa ser limitada pelo direito natural.

Desse pensamento pode ser extraída a principal exigência dos direitos humanos - como proclamados nas diversas modernas declarações de direitos (francesa, americana e universal) -, segundo a qual a soberania de um Estado 
não pode criar todo e qualquer direito. Esses direitos partiram exatamente da compreensão de que nem toda vontade do Estado configura-se propriamente como direito, pois o Estado também está limitado pela natureza das coisas - no caso, pela natureza das pessoas.

O pensamento de Tomás de Aquino é essencial para fundamentar e esclarecer essa limitação. Em sua visão era primordial distinguir o natural do convencional. A diferença entre o que é necessário e o que é contingente marca a separação entre a lei humana e a lei natural (RAMPAZZO; NAHUR, 2015, p. 11). Como conclusão, o poder humano não pode tudo, pois há uma verdade objetiva na realidade, própria das coisas como elas são (de modo natural e necessário).

Sendo que, a considerar que o jurista tem a função de aplicar o direito e não simplesmente a lei, ele deve buscar o resultado justo (o direito) por todos os meios disponíveis - ainda que isso implique a não aplicação da lei positiva.

Aquino é enfático ao afirmar que "toda lei humanamente imposta tem tanto de razão de lei quanto deriva da lei da natureza. Se, contudo, em algo discorda da lei natural, já não será lei, mas corrupção de lei" (AQUINO, 2015, III, q. 95). Como critério de validade das leis positivas, seu pensamento fundamenta inclusive quando cortes de direitos humanos reputam determinadas leis como a própria negação do direito (CORTE INTERAMERICANA DE DIREITOS HUMANOS, 2001).

No entanto, esse posicionamento não implica que o pensamento tomista seja baseado em um universalismo simplório. Realmente, um ponto essencial na discussão atual sobre os direitos humanos é como encontrar uma solução entre o universalismo e o relativismo (KLAUTAU FILHO, 2004, p. 36). No pensamento de Tomás a solução é dada por um meio termo existente na relação entre a lei natural e a lei positiva.

Nesse aspecto, sua posição busca ser harmônica com as forças históricas, considerando que o mundo não é estático - ao contrário, "é, antes, um organismo de forças históricas mutáveis" (VOEGELIN, 2012, p. 249). Para efetivar a justiça é preciso compreender que a realização do direito se dá no mundo historicamente concreto num dado momento. Então, fica claro que as 
leis devem adequar-se ao justo, à natureza, aos costumes, ao lugar e ao tempo (AQUINO, 2015, I-II, q. 95).

Portanto, a filosofia tomista não cai em um relativismo, ao considerar a igualdade por natureza; mas também não ignora as contingências, ao reconhecer a mutabilidade do mundo. Os direitos humanos poderiam, portanto, considerar as particularidades de cada povo, sem reconhecer que toda manifestação cultural é válida - vencendo o despotismo dos costumes. Ao mesmo tempo, deixariam de servir a um discurso imperialista ocidental para impor determinado modelo de vida ao restante do mundo.

Essa concepção permite que as mais diversas comunidades reconheçam os direitos humanos, aplicando-os da forma possível no seu contexto particular. No contexto internacional, a posição tomista incentiva a positivação dos direitos humanos que, conforme as circunstâncias, podem ser exigidos de todos os países. No contexto local, os direitos humanos fundamentam a rejeição de práticas - ainda que culturais - que se mostram irracionais e lesivas à pessoa.

Ora, a lei natural pressupõe uma ideia de pessoa humana, que se concretiza principalmente a partir das noções de igualdade e alteridade. A visão tomista é de que a "pessoa humana é um ser concreto, individual, racional e social" (RAMPAZZO; NAHUR, 2015, p. 134). O centro dessa ideia é de que os homens são criaturas racionais.

A alma do ser humano caracteriza sua unidade substancial, que é concreta por existir efetivamente. Ele é um ser que busca o bem não por instinto, como as criaturas irracionais, mas por intermédio de sua liberdade. Por ser livre, o homem pode fazer escolhas, decidindo com base em sua razão. A vontade, nesse sentido, não é um impulso, pois é guiada racionalmente (RAMPAZZO; NAHUR, 2015, p. 15).

Como conclusão, a pessoa não é criada pelo direito positivo, por ser anterior a ele - e seu fundamento (HERVADA, 2006, p. 54). O direito existe em razão da pessoa humana, o verdadeiro fundamento da titularidade de direitos. Hervada (2006, p. 77) assim descreve esse paradoxo da criação do sujeito de direitos pelo próprio direito: 
Dizer que a condição de sujeito de direito é dada pela lei humana é uma afirmação vazia por sua radical impossibilidade: o homem daria a si mesmo a potência (a capacidade para o fato cultural) e o ato (o fato cultural), o que suporia nele um poder criador em sentido estrito (tirar algo do nada), coisa impossível.

Portanto, é necessário que o direito natural assegure essa condição de titular para que possam ser criados e gozados os direitos positivos. Logo, a igualdade entre os homens não reside na lei humana, e sim em razão da natureza das coisas. A humanidade foi dotada pelo criador de uma igualdade, por analogia (RAMPAZZO; NAHUR, 2015, p. 12).

Sendo a justiça uma virtude relacional, tal igualdade exige alteridade. Isto é, o direito exige o reconhecimento da pessoa do outro e de sua condição de sujeito de direitos, que constituem deveres para os demais. Há um vínculo de reciprocidade na comunidade que faz com que cada um espere ser tratado como pessoa humana, do mesmo modo como é capaz de tratar o outro (RAMPAZZO; NAHUR, 2015, p. 133-134).

Portanto, há o reconhecimento de que o eu está em débito com o outro deve aquilo que é justo -, que possui a mesma natureza de sujeito de direitos. A virtude e a racionalidade, assim sendo, exigem o reconhecimento do outro, o reconhecimento do direito do outro e, por fim, a entrega ao outro daquilo que Ihe pertence, o que realiza o justo.

Essa igualdade não trata os seres humanos de forma abstrata, ao contrário, considera suas particularidades. Isso, pois a justiça consiste não em criar a identidade entre as pessoas na forma de um igualitarismo, e sim a equivalência que considera a diferença entre as pessoas (HERVADA, 2006, p. 31). Deve ser dado aquilo que é devido, não a mesma coisa a todos. Dar o devido pressupõe consideração da pessoa com suas individualidades, e não descolada de seu contexto.

Como é possível concluir, esses conceitos de pessoa, alteridade e igualdade vão ao encontro dos direitos humanos. A defesa tomista de ser humano atende o estrito objetivo das declarações de direitos ao dirigir o Estado e o poder político à tutela da pessoa. Mais, a sociedade e as demais pessoas tornam-se codevedoras do respeito e da garantia dos direitos dos demais, pois essa é uma exigência e uma decorrência da humanidade compartilhada entre os homens (BARZOTTO, 2010, p. 64). 
Embora no pensamento antropológico de Tomás de Aquino o homem constitua uma unidade, a sua plenitude somente é alcançada em comunidade. As capacidades racionais da pessoa não se desenvolvem de forma plena isoladamente ou apenas em família (VOEGELIN, 2012, p. 253).

Sendo que diferentemente da concepção de Thomas Hobbes (1993, p. 175) - o pai do positivismo político moderno -, essa comunidade é marcada pela liberdade dos homens. Essa liberdade deve ser utilizada na busca do bem comum, pelo que a comunidade é cooperativa (VOEGELIN, 2012, p. 254-255). Sendo assim, cada um deve à sociedade sua cota de participação na obtenção do bem comum, o que constitui o dever de justiça de cada cidadão, que está fixado na lei (HERVADA, 2006, p. 89-90).

Nesse sentido, não pode ser afirmado que os direitos humanos contemporâneos estão afastados do pensamento tomista em razão de terem sido pensados como mecanismos de defesa contra o Estado Moderno. Embora o conceito de soberania estatal existente ao tempo das principais declarações de direitos dos séculos XVIII-XX não tivesse sido desenhado na época de Tomás de Aquino, o conceito de comunidade política não pode ser considerado completamente dissonante.

Aliás, Eric Voegelin (2012, p. 269) já identifica em Tomás de Aquino as bases que vão determinar a história política do Ocidente, como "o povo organizado com constituição, a sociedade comercial burguesa, o espiritualismo da Reforma e o intelectualismo da ciência".

Efetivamente, no pensamento tomista a comunidade tem um papel relevante de buscar o bem comum. Sendo assim, não busca o bem de um, de alguns ou da maioria, e sim de forma geral (RAMPAZZO; NAHUR, 2015, p. 11). Portanto, é uma sociedade onde o justo é observado e onde as virtudes são incentivadas. $O$ fundamento da autoridade não é a força bruta e o poder não é ilimitado. A lei natural baliza o funcionamento das instituições.

Logo, esse pensamento pode ser ajustado à compreensão atual de Estado. Os direitos humanos tiveram sua explosão exatamente em contextos de violação do justo natural pelo Estado e pelas autoridades, que usaram o poder e a força sem observar critérios de bem comum - observe-se que o bem 
comum não se confunde com o bem da maioria, como ocorre no utilitarismo - e sem atender o justo fixado pela lei natural.

Pode ser observado que em Tomás de Aquino a relação entre o direito, a justiça e a lei permite o fundamento dos direitos humanos no estrito sentido em que foram defendidos, como instrumentos para o ajustamento nas relações sociais e, dessa forma, a busca da paz na sociedade (HERVADA, 2006, p. 23). E tal como a justiça, estes direitos não estão voltados a grandes massas indistintamente, mas considera cada relação social específica (HERVADA, 2006, p. 35). Sendo que nem a justiça nem dos direitos humanos devem ser pensados como utópicos (HERVADA, 2006, p. 10).

\section{Conclusão}

Em tempos de incerteza, os arquipélagos de certeza garantem ao homem mais do que segurança e estabilidade, garantem uma sensação de paz. Essa é uma das razões que torna a positivação tão atraente, por ser mais fácil de manusear do que a exigência de um exercício profundo da razão. Além disso, o homem se sente no completo controle sobre o justo e o injusto.

No entanto, os direitos humanos vêm mostrar exatamente o contrário, que $o$ direito pode ser um instrumento de grande mal se não for adequadamente controlado e se não tiver um fundamento sólido. $E$ isso não é suficientemente respondido afirmando que o direito é fruto unicamente da vontade humana. É necessário, portanto, buscar as razões assentadas no justo natural.

Nesse sentido, é possível perceber que a compreensão do positivismo jurídico segue o oposto do pensamento de Tomás de Aquino. Como visto, quando o positivismo restringe os direitos humanos à positivação dos Estados ou da Comunidade Internacional, acaba por nulificar o conceito que foi historicamente desenhado. O positivismo acaba exatamente na confusão entre o ideal e o direito.

Uma proposta de fundamentação dos direitos humanos precisa abrir mão do positivismo e adotar uma lei positiva como entendida pelo tomismo. Efetivamente, o pensamento de Tomás de Aquino anuncia os direitos humanos 
na exata medida em que não confunde o que é devido com aquilo que as pessoas reivindicam. Enquanto uma pretensão tem por fundamento argumentos que não a justiça, um direito existe por ser devido, por ser objeto da justiça. A igualdade natural da humanidade tem como consequência mais do que pretensões simpáticas à opinião pública; tem como consequência direitos mínimos.

Para concluir, é válido um exemplo: a vida é uma pretensão ou um direito? À luz do positivismo é uma pretensão que passa a ser direito se acolhida por uma decisão política. Por sua vez, a resposta de Tomás de Aquino - que é exatamente a luta dos direitos humanos - é de que a vida é devida à pessoa. Sendo devida, é um direito e, portanto, é dever da comunidade, das autoridades e dos demais reconhecê-lo e assegurá-lo - pois estão em débito em relação a ele.

Em sendo assim, os direitos humanos encontram um firme fundamento no pensamento tomista, pois Tomás de Aquino foge do subjetivismo que reduz todo o direito a uma decisão da vontade humana. Também se afasta do ceticismo que nega que a lei natural possa ser objetivamente conhecida. Por fim, seu pensamento não cai no normativismo que equipara o direito à lei. Portanto, sem desconsiderar a relevância da lei positiva, os direitos humanos poderiam enfrentar as principais violações à pessoa, que muitas vezes são perpetradas pela letra da lei.

\section{Referências}

AQUINO, Tomás de. Suma Teológica. Vol. 4 e 6. 3. ed. São Paulo: Edições Loyola, 2015.

BARZOTTO, Luis Fernando. Filosofia do Direito: os conceitos fundamentais e a tradição jusnaturalista. Porto Alegre: Livraria do Advogado, 2010.

BASTIT, Michel. Nascimento da lei moderna. São Paulo: WMF Martins Fontes, 2010.

BOBBIO, Norberto. A Era dos Direitos. Rio de Janeiro: Elsevier, 2004. $1995 a$

. O Positivismo Jurídico: Lições de filosofia do direito. São Paulo: Ícone, 
. Teoria da norma jurídica. Bauru: EDIPRO, 2001.

Teoria do ordenamento jurídico. 6. ed. Brasília: Editora Universidade de Brasília, 1995b.

CORTE INTERAMERICANA DE DIREITOS HUMANOS. Caso Barrios Altos vs. Peru. Mérito. Sentença de 14 de março de 2001. Disponível em:

$<$ http://www.corteidh.or.cr/cf/Jurisprudencia2/busqueda_casos_contenciosos.cf m?lang=es $>$. Acesso em: 30/07/2015.

FINNIS, John. Fundamentos de ética. Rio de Janeiro: Elsevier, 2012.

HART, H. L. A. O conceito de direito. São Paulo: Editora WMF Martins Fontes, 2009.

HERVADA, Javier. O que é o direito? A moderna resposta do realismo jurídico. São Paulo: WMF Martins Fontes, 2006.

HOBBES, Thomas. De cive: elementos filosóficos a respeito do cidadão.

Petrópolis: Vozes, 1993.

ISRAËL, Nicolas. Genealogia do Direito Moderno: o estado de necessidade. São Paulo: WMF Martins Fontes, 2009.

KELSEN, Hans. Teoria pura do direito. 8. ed. São Paulo: Editora WMF Martins Fontes, 2009.

KLAUTAU FILHO, Paulo de Tarso Dias. Igualdade e Liberdade: Ronald Dworkin e a Concepção Contemporânea de Direitos Humanos. Belém: CESUPA, 2004.

MARITAIN, Jacques. O homem e o estado. 4. ed. Rio de Janeiro: Agir, 1966.

NINO, Carlos Santiago. Ética e Direitos Humanos. São Leopoldo: Editora Unisinos, 2011.

RAMPAZZO, Lino; NAHUR, Március Tadeu Maciel. Princípios jurídicos e éticos em São Tomás de Aquino. São Paulo: Paulus, 2015.

RAWLS, John. Uma teoria da justiça. 3. ed. São Paulo: Martins Fontes, 2008.

RAZ, Joseph. O conceito de sistema jurídico: uma introdução à teoria dos sistemas jurídicos. São Paulo: WMF Martins Fontes, 2012.

ROBLES, Gregorio. Os Direitos Fundamentais e a Ética na Sociedade Atual. Barueri: Manole, 2005.

STRAUSS, Leo. Direito Natural e História. São Paulo: Editora WMF Martins Fontes, 2014. 
VOEGELIN, Eric. História das ideias políticas: Idade Média até Tomás de Aquino. Vol. 2. São Paulo: É Realizações Editora, 2012. 